\title{
Quo vadis CNR?
}

\section{László Solymosi ${ }^{1}$}

It has already become a tradition to report on our journal's development in every third issue of an ongoing year. Reporting on the successful development of Clinical Neuroradiology has been a very pleasant duty for the last 5 years and there are further good news this year I would like to share with you.

In the middle of each year, the latest Impact Factor for the previous year is published. Clinical Neuroradiology has greatly improved in all areas in comparison to the average for all scientific journals listed. Our journal's current impact factor lies at 2.887. The values in the years since first receiving an impact factor are shown in Fig. 1. The red curve shows a trend that certainly gives grounds for con- fidence in the future and hopefully is able to answer the question raised in the title of this editorial.

Clinical Neuroradiology is listed in 2 categories. In both of these categories, the journal continues to rise in rank. In the "Clinical Neurology" category our journal is ranked 67 out of 192 journals in total (see Fig. 2); in the "Radiology, Nuclear Medicine \& Medical Imaging" category, Clinical Neuroradiology ranks 30 out of 124 listed journals (Fig. 3).

As the figures clearly show, our journal has established itself in the international scientific world, thanks to the numerous good papers submitted for publication! We hope that you will continue to support our journal in the future
Fig. 1: Development of the impact factor of Clinical Neuroradiology and calculated trend

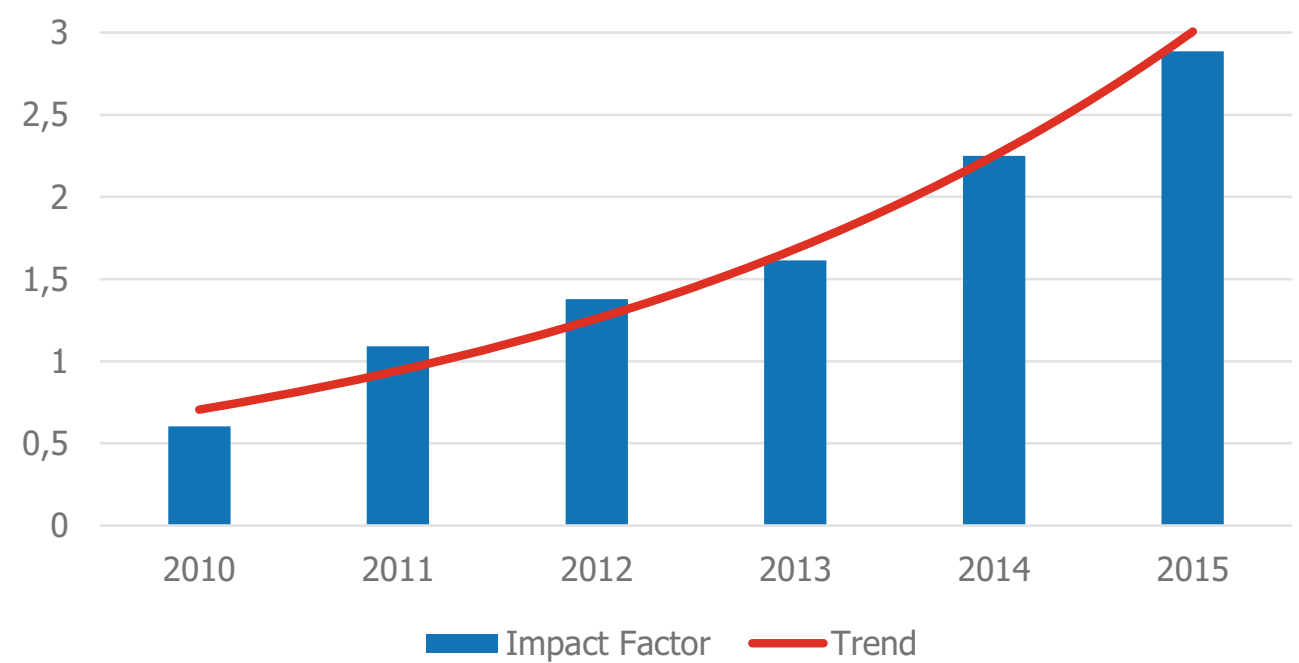

László Solymosi solymosi_1@ukw.de

1 Dept. of Neuroradiology, University Hospital of Würzburg, Würzburg, Germany 
Fig. 2: Clinical Neuroradiology's development in the "Clinical Neurology" category

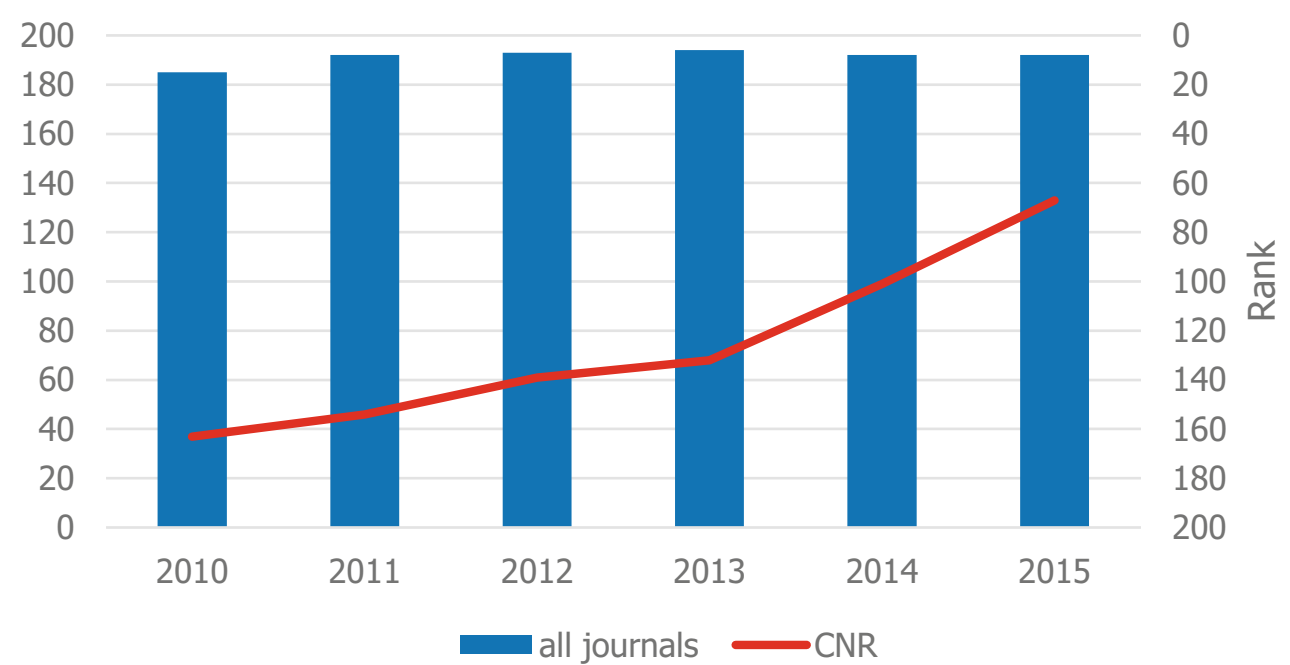

Fig. 3: Clinical Neuroradiology's development in the "Radiology, Nuclear Medicine \& Medical Imaging" category

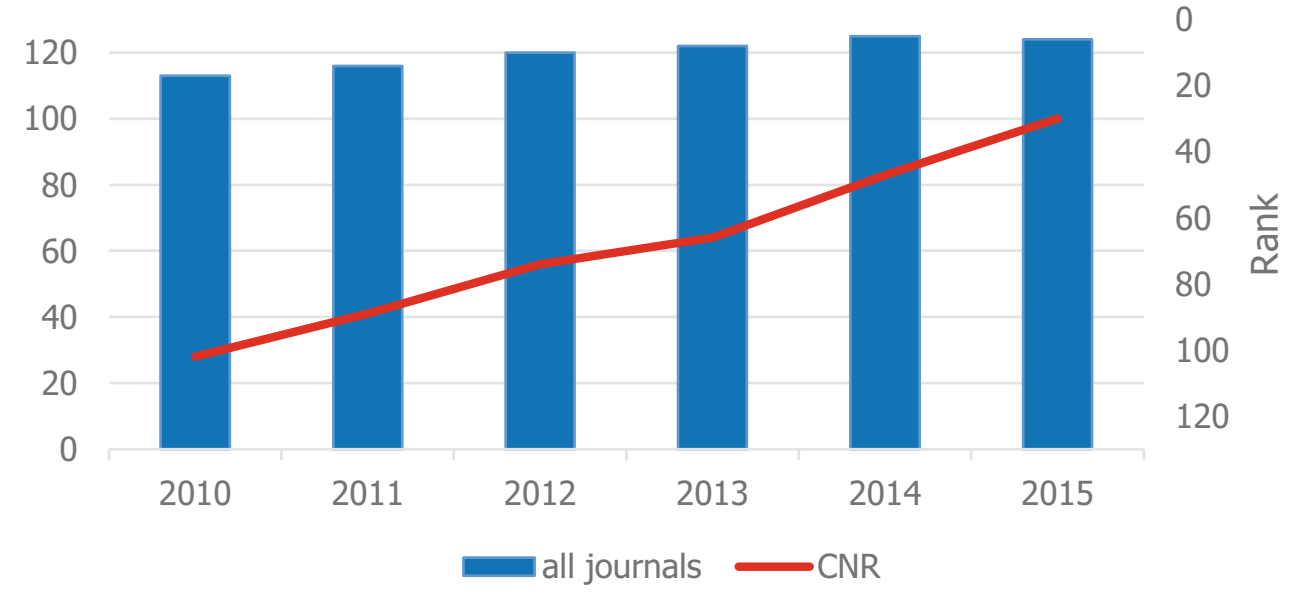

in order to ensure that it maintains its excellent position among the best international scientific journals.

On behalf of the publisher and the editorial board, I would like to thank you for your valued support!

\section{László Solymosi}

Editor-in-Chief

Conflict of interest L. Solymosi declare that he has no competing interests. 